Rev. Latinoam. Psicopat. Fund., São Paulo, 18(2), 352-368, jun. 2015

http://dx.doi.org/10.1590/1415-4714.2015v18n2p352.12

\title{
Psiquiatria e nomeação
}

\author{
João José R. L. de Almeida*1
}

Quanto mais intensas as discussões sobre as classificações \begin{abstract}
psiquiátricas, mais exigente se torna a necessidade de uma atenção cuidadosa sobre a lógica pela qual se enquadra e se desenvolve a clínica dos transtornos mentais. Seus problemas especificos de nomeação deveriam ser resolvidos pelo instrumento de trabalho mais adequado para este tipo de tarefa, que deveria ser, considerando a sua natureza, uma lógica plurivalente. Em vista disso, discuto aspectos lógicos da proposta de Peter Zachar conhecida como nominalismo instrumental.
\end{abstract}

Palavras-chave: Psiquiatria, nomeação, nominalismo instrumental, DSM-5

${ }^{* 1}$ Universidade Estadual de Campinas - Unicamp (Limeira, SP, Br) 
Numa publicação recente, o historiador da psiquiatria Mark S. Micale (2014) divulgou os resultados de uma enquete aplicada individualmente a cerca de duzentos especialistas em saúde mental americanos na qual ele solicita uma resposta espontânea sobre quais foram, na sua visão, as dez mais importantes mudanças na psiquiatria desde a Segunda Guerra Mundial. A maioria dos respondentes percebeu as seguintes modificações, aqui resumidas:

1. A "revolução psicofarmacológica" dos anos 1950.

2. A desmanicomialização de um massivo número de pacientes psiquiátricos.

3. O "declínio" e a "queda" da psicanálise.

4. A prática psicoterápica passou a incluir profissionais não médicos: psicólogos e assistentes sociais.

5. Um vasto crescimento dos programas de pesquisa em neuroquímica e neurobiologia das doenças mentais.

6. A introdução e a ampla adoção de uma nova geração de agentes ansiolíticos e antidepressivos, especialmente os assim chamados ISRS (inibidores seletivos de recaptação da serotonina), como, por exemplo, a fluoxetina.

7. Um aumento vigoroso da influência da indústria farmacêutica na psiquiatria.

8. O crescimento da influência do DSM (Manual Diagnóstico e Estatístico de Transtornos Mentais).

9. A multiplicação de "novos" diagnósticos.

10. A despatologização da homossexualidade.

Esta lista expõe, no mínimo, duas informações crucialmente relevantes para a psiquiatria em geral: em primeiro lugar, o recrudescimento da sua responsabilidade social e política; e, em segundo lugar, a mudança de foco epistemológico, que deslocou a predominância da visão psicodinâmica para a perspectiva psicofarmacêutica na disciplina. À importância social e política e à mudança de foco epistemológico, percebida pelos respondentes, podemos somar ainda mais um fato que não apareceu na 
enquete: a publicação em 2013 da 5a edição do DSM (DSM-5), já estruturada para harmonizar com as classificações da CID-11 (Classificação Estatística Internacional de Doenças), a ser lançada em 2017.

Provavelmente por motivos como esses, cada nova edição do DSM reacende a literatura, já muito vasta, da discussão acerca da realidade e da objetividade das classificações dos transtornos mentais. Realidade e objetividade são conceitos metafísicos diretamente relacionados às respostas da enquete. Ao fato de que agora, sem contar a pressão exercida pela indústria farmacêutica, os transtornos mentais definidos pelo DSM vêm ratificados inclusive pela sua harmonização com a CID, o que suscita ainda maior responsabilidade social.

Vamos admitir que um contexto como este seria, no mínimo, conturbado. Basta lembrar que se homossexualidade e personalidade múltipla já foram transtornos claramente definidos pelo DSM, e hoje desapareceram completamente do manual, não teríamos praticamente como não imaginar que outras classificações hoje em voga não pudessem ser também efêmeras. Ou que se um grupo de sintomas definiu por milênios uma certa figura psicopatológica denominada como "histeria" (Micale, 2008), que foi simplesmente apagada do DSM na sua terceira edição, em 1980, ou, pelo menos, teve o seu grande grupo de sintomas diluído entre várias outras definições de transtornos mentais, criados mais recentemente, não teríamos como não presumir que aqueles que agora lá estão não sejam também futuramente eliminados ou diluídos. Ou que se um transtorno como o de estresse pós-traumático foi introduzido no manual somente depois da guerra do Vietnã, tampouco teríamos como não supor que suas evidências não sejam realmente plausíveis ou que sua verdade não seja realmente verificável. Ficamos com uma impressão razoável de que, do ponto de vista da realidade e da objetividade efetivas dos transtornos mentais, pisamos hoje em dia em um mundo gasoso habitado por entidades fantasmagóricas.

Se tomamos o grupo dos transtornos depressivos, por exemplo, sempre fortemente associados a aspectos culturais, que hoje em dia o DSM reconhece plenamente, a sensação de irrealidade não melhora. Se os aspectos culturais são fatores considerados pelo DSM, por que então o transtorno depressivo maior se diferencia no manual pela presença de cinco entre nove sintomas destacáveis? (cf. Zachar, 2014, p. 227). Qual é a relação entre a conta matemática e a psicologia, isto é, como evidenciá-la e como justificá-la, sobretudo em face de um conjunto de sintomas tão afetados culturalmente? Em suma, a pergunta de fundo é: o que podemos dizer de concreto e de decisivo atualmente sobre a psiquiatria como parte da ciência e como agente eficiente da saúde mental, dadas a aparente volatilidade e a precariedade das suas evidências empíricas, além da relatividade dos fatores culturais eventualmente associados aos sintomas básicos de cada transtorno?

No universo da discussão filosófica da psiquiatria, o tema da realidade e da objetividade dos transtornos mentais comporta várias linhas teóricas distintas. Entre 
os seus polos opostos se estendem posições que vão desde a proposta antirrealista defendida por Thomas Szasz (1974) até a posição de um realismo substancializado defendido por George Graham (2010). Para o primeiro, os transtornos mentais são apenas mitos, seus nomes denotam somente comportamentos e o psiquiatra não é mais que um agente de controle social. Para o último, os conceitos de transtornos mentais compreendem normas semânticas reais que indicam uma presença prejudicada da razão ou da racionalidade.

Como consequência do fato de que quase a totalidade dos trabalhos de filosofia da psiquiatria vai se diferenciar em relação simultânea aos dois pontos extremos, uma pletora de distintas perspectivas regularmente se autodenomina como de "meio termo" (Ross, 2005, p. 115). Naturalmente, cada uma delas tem os seus matizes filosóficos particulares, mas curiosamente todas têm de si a mesma visão virtuosa em termos aristotélicos. Desejo destacar aqui, no entanto, apenas uma delas, de teor pragmatista, com a qual concordo na sua maior parte e que, no Brasil, foi objeto de um artigo publicado há um ano por Banzato \& Zorzanelli (2014), e de outro publicado há alguns meses por Serpa Jr. (2014). Trata-se do nominalismo instrumental proposto por Peter Zachar (2014), uma atualizada e excelente análise dos problemas filosóficos da psiquiatria. Com aquele trabalho podemos visualizar proveitosamente a peculiar situação epistemológica desta especialidade médica.

A proposta filosófica de Zachar consiste numa recondução a condições empíricas radicais em que princípios transcendentais da investigação científica, como os conceitos de realidade, objetividade, evidência e verdade, utilizados na heurística e na justificação dos programas de pesquisa, somente são válidos na medida em que funcionam como instrumentos a serviço dos interesses e preferências da comunidade de pesquisadores. Zachar supõe, a meu ver acertadamente, que pode evitar assim tanto o essencialismo das propostas mais afeitas a fundamentações exclusivas nas ciências naturais quanto os relativismos que se baseiam exclusivamente no construtivismo social. Seu modelo é chamado de "comunidade imperfeita", e sua proposta se circunscreve ao que denomina como "pragmatismo científico".

Neste artigo gostaria de discutir alguns aspectos lógicos da solução apresentada por Zachar e, se for possível uma ousadia, colocar pequenos reparos de modo a indicar o que seria, a meu ver, uma proposta mais robusta, de acordo com a sua própria perspectiva, para os desafios contemporâneos da psiquiatria.

\section{O nominalismo instrumental}

A exemplo de qualquer daquelas discussões filosóficas de termo médio, a lógica do nominalismo instrumental também pretende dar conta das noções de (a) 
realidade e de (b) objetividade dos transtornos mentais. Mas não somente dessas noções, como também de conceitos correlacionados como os de (c) evidência empírica e de (d) verdade desses transtornos, além da noção de (e) progresso científico em psiquiatria.

Que virtudes Zachar (2014) pretende ressaltar com o termo "nominalismo instrumental"? Sua preocupação evidencia-se naturalmente pela própria afirmação filosófica. Trata-se de escapar dos abstracionismos e dos essencialismos eventualmente inerentes aos nomes, ou melhor, às nomeações. O autor lembra a antiga tradição antiplatônica do nominalismo: "nominalistas advogam por uma atitude antiplatônica a respeito de conceitos filosóficos abstratos tais como virtuoso, verdadeiro, bom e livre" (p. 41). Como num velho adágio kojeviano, aliás repetido à exaustão como um mantra por muitos seguidores de Lacan, a ideia de fundo é a de que "o nome é a morte da coisa". Seria como se reconhecêssemos na denominação, no ato de nomear, uma separação definitiva do mundo concreto, da particularidade, do individual, combinada com uma alienação inevitável no espaço sem alma da universalidade.

Zachar tem um propósito semelhante, mas sem os dogmatismos que caracterizam algumas produções teóricas da psicanálise. Por isso mesmo o seu nominalismo aparece qualificado como "instrumental". O que quer dizer que procura ser "menos austero" (p. 42), ou seja, não quer comprometer a inteligência com o paradoxo assumido pela tese, também abstrata, de que nada haveria de significativo no agrupamento de uma série de enunciados verdadeiros sobre objetos ou eventos particulares. O nominalismo, em versão instrumental, atribui valor positivo à conceitualização de grupos de eventos ou objetos particulares sob uma denominação única e comum. Nada haveria de errado em princípio no uso de tipos naturais como "genes", "moléculas" ou "neurotransmissores", ou em enunciados científicos como "o número de átomos em $12 \mathrm{~g}$ de carbono é 6,02 x 1023”. Sua reivindicação é, antes, uma adesão radical à experiência, sem nada reclamar especificamente quanto ao ato de nomear, por si mesmo. Quer dizer, admite-se como legítima e necessária uma metafísica rigorosamente restrita aos limites do empírico ou do palpável - mesmo que nada que componha a microfísica seja passível de verificação direta ou, digamos assim, palpável. Verificações indiretas, por via de aparelhos complexos e sofisticados, e o consenso da comunidade científica, são aceitos como parte do conjunto epistêmico. Além disso, como consequência do empirismo radical, Zachar defende que deve haver várias maneiras diferentes de organizar a experiência, de modo que os conceitos de realidade, objetividade, evidência e verdade (as noções (a), (b), (c) e (d) acima) têm foros de plena cidadania na atividade de pesquisa científica, inclusive da psiquiatria, desde que se ponha a descoberto que sua vida civil é sempre relativa a algum interesse ou propósito em organizar a experiência sob determinados nomes e formas particulares.

Desta maneira, todas essas noções são importantes e perfeitamente legítimas para a ciência. Deixam de ser operacionalizáveis apenas quando são tomados como 


\section{OBSERVANDO A PSIQUIATRIA}

princípios transcendentais intocáveis. A realidade e a objetividade de um objeto científico, mas também as suas evidências e o que se considera como verdade, além de serem relações empíricas, são também, como era de se esperar, relativas ao consenso de uma comunidade de especialistas, conforme veremos. Precisamente neste sentido, Zachar debate em seu livro as críticas antirrealistas de Szasz em torno do curioso transtorno denominado como "drapetomania". Figura proposta em 1851 pelo médico Samuel Cartwright para caracterizar a compulsão de fuga que "acometia" alguns escravos negros (Zachar, 2014, pp. 126-128). Para o autor, racismo, sexismo e homofobia surgem e desaparecem das constelações de sintomas relevantes em psiquiatria no decurso da história exatamente deste modo. A relevância de um transtorno mental estaria sempre sujeita ao uso e ao interesse coletivo e, por isso mesmo, sua aplicação poderia sofrer mudanças de tempos em tempos, em função do debate e da crítica constante da comunidade sobre suas próprias definições. $\mathrm{O}$ que diria que talvez aconteça bem mais regularmente na psiquiatria do que nas outras ciências.

Mas um modelo tão relativista, como já disse, é algo que Zachar prefere evitar tanto quanto o seu lado oposto, o essencialismo. Para dar conta deste problema, o autor faz uso do tratamento mereológico ${ }^{1}$ dado por Nelson Goodman (1951) aos fenômenos particulares e suas relações de pertencimento e de inclusão em diferentes conjuntos. O recurso foi usado por Goodman para evitar a "dificuldade da comunidade imperfeita" (Goodman, 1972, p. 150) que bloqueava a sua busca por uma maneira adequada de definir qualidades (como cores) em termos de elementos concretos. Zachar (2014), por sua vez, denominou o recurso como "modelo da comunidade imperfeita” (pp. 121-128). Em termos práticos, isto significa dizer que os transtornos mentais constituiriam uma comunidade imperfeita porque "não há nenhum conjunto de propriedades que todos os transtornos psiquiátricos compartilhem e que os distinga de não transtornos" (pp. 42, 125). Isto é, representamos o pertencimento dos sintomas com conjuntos impuros, digamos assim, porque nem todas as propriedades são comuns. Alguns sintomas e grupos de sintomas mantêm entre si relação mútua e outros não, mas a noção de comunidade sugere que a coleção não é simplesmente fortuita ou arbitrária. Haveria razões para justificá-la. Em termos conceituais, contudo, é bastante importante entender que se trata também, no fundo, de uma comunidade (para usar a mesma palavra, agora em

${ }^{1}$ A mereologia é o estudo lógico de inspiração nominalista das relações entre as partes e os todos que aquelas eventualmente conformam. Na prática, substitui-se, em teoria dos conjuntos, a versão abstrata e tradicional do estudo da relação entre o todo e as suas partes, pelo estudo mais concreto da relação entre as entidades particulares e os seus conjuntos possíveis. 
sentido sociológico) de especialistas que bem ou mal irá prover uma estrutura suficiente e necessária para que as distinções sintomáticas sejam de interesse para diferenciar um transtorno mental. ${ }^{2}$

Esta importante solução proposta pelo autor se faz em torno de critérios não essencialistas e não relativistas, tomadas estas definições em termos absolutos, restritos aos dados empíricos e a algumas inferências a variáveis latentes. Os critérios de Cartwright, na Louisiana do século XIX, por exemplo, eram apenas três: a biologia racista do seu tempo, as Sagradas Escrituras e a sua própria experiência médica. Os nossos, hoje em dia, são outros e muito mais amplos. Em outras palavras, o que se considera "objetivo" e "real" só vem à luz contra o pano de fundo de uma totalidade de supostos indiscutíveis que servirão de medida para o convencimento e para a aceitação da comunidade de especialistas de um certo período histórico. Neste sentido, o que nos parece absurdo surge apenas da comparação retrospectiva entre os critérios do século XIX e os nossos. Contudo, não enxergamos a falta de fundamento dos nossos próprios critérios - e nem poderíamos, talvez. Como, por exemplo, a ideia de associar injustificadamente o conceito matemático de "maior que", presente de modo tácito na definição do transtorno depressivo maior do DSM-5, com uma série de sintomas psicológicos. A regra matemática é o instrumento usado para fundamentar a inferência de que cinco elementos são maioria num conjunto total de nove elementos. Mas qual é a conexão entre uma "maioria", um critério eminentemente matemático, e o que seria relevante para um "transtorno mental" naturalmente avesso à mensuração?

O importante no modelo da comunidade imperfeita é ressaltar que um conjunto de sintomas, que seja relevante para definir um transtorno mental atende tanto a

${ }^{2}$ Por que vale a pena separar o aspecto empírico do tratamento dos particulares e seus possíveis conjuntos do seu aspecto conceitual? Porque evidentemente o "modelo da comunidade imperfeita" também implica, no plano conceitual, um recurso lógico final ao consenso de uma "comunidade de especialistas". Afinal, quem iria circunscrever os conjuntos relevantes para as amostras empíricas que não compartilham propriedades comuns e evitar a trivialidade deste recurso lógico? Este consenso traduz-se logicamente como axiomas do sistema. Repare o leitor que, na p. 122, Zachar revela que "A questão, para o pragmatista, é que distinções estão fazendo um bom trabalho e por quê..." e que "O que se busca [é uma arregimentação] que proporcione uma armação (...) que seja de interesse (...)". Na p. 128, ele também diz que "O modelo da comunidade imperfeita proporciona uma base conceitual para interpretações não essencialistas dos DSMs que tenham sido favorecidas por muitos dos seus arquitetos ao longo dos anos". E, finalmente, na p. 123, acrescenta que "De acordo com Goodman, não existe nenhuma lista a priori e predeterminada de tipos lá fora esperando para serem descobertos; em vez disso, a multiplicidade de coisas do mundo podem ser combinadas de diferentes modos, e que combinações são consideradas relevantes depende dos nossos propósitos." 


\section{OBSERVANDO A PSIQUIATRIA}

interesses de tratamento quanto a interesses políticos. E nada disso quer dizer que o aspecto empírico, e portanto objetivo da questão, não seja importante. O ponto aqui não é a arbitrariedade da metodologia científica, objeto da crítica de Szasz especificamente quanto ao relativismo inerente à psiquiatria. $\mathrm{O}$ que Zachar chama de comunidade imperfeita responde, na realidade, ao aspecto fortemente normativo e convencional das definições face ao seu aspecto objetivo e ao fato de que elas estão permanentemente sujeitas a revisões. A sua discussão não é sobre que classificação seria exatamente a mais real, nem a que mais se coadunaria com qualquer outra abstração que possamos eleger como significativa. Faltaria um critério independente para aferir o valor objetivo desta ou daquela abstração. O meritório na sua solução é, portanto, nos lembrar que temos de nos conformar que aquilo que chamamos de "objetivo", "real", "verdadeiro" e "evidente" não paira acima dos contextos históricos e da experiência percebida pela comunidade científica. Para Zachar trata-se simplesmente do exame de um amplo grupo de casos concretos do que supostamente representaria problemas vivenciais que sejam ou não havidos por "transtornos" (por exemplo, luta pela liberdade ou por melhores condições de trabalho, no caso da drapetomania). Isso implica o exame de uma rede causal tão ampla quanto possível de variáveis observáveis e latentes que poderiam se encaixar simultaneamente em várias denominações. Implica visar metas múltiplas e competidoras de classificações psiquiátricas. Implica ampliar e variar em máximo grau supostas redes causais dos sintomas. E implica também colocar em relação mútua e fechada os tipos naturais, os tipos práticos, os conceitos históricos e os conceitos normativos para conformar o que seria, na sua perspectiva, um instrumento heurístico suficientemente apropriado para estabelecer as melhores classificações psiquiátricas dentro de um contexto histórico e normativo (Zachar, 2014, pp. 137-156). O mais real, o mais objetivo, o que comporta mais evidências e o mais verdadeiro são definidos no interior dos critérios possíveis. Não posso me estender aqui com os exemplos concretos, mas remeto o leitor à consulta do material relevante aplicado ao caso da tristeza e dos transtornos depressivos (pp. 157-179).

A noção de progresso em psiquiatria dentro do modelo da comunidade imperfeita (o quesito (e) acima) tampouco corresponde a uma definição mais real, mais perfeita ou que mais se aproxima à verdade de um determinado transtorno. Se um transtorno mental servir num certo contexto histórico e normativo para traçar distinções mais informativas na nossa experiência (p. 217), ou se uma determinada classificação é colocada a teste contra outras crenças que com ela competem, e ela, a longo prazo, sobrevive às demais, poderíamos aceitar, relativamente àquela perspectiva, também a noção de progresso (pp. 207-208). Neste sentido, o quesito (e) se integra e se correlaciona empiricamente, mas não como abstração isolada, com os quesitos (a), (b), (c) e (d). Na gramática proposta por Zachar, as regras põem em correlação as oposições dos tipos naturais contra os tipos práticos, e dos conceitos históricos 
contra os conceitos normativos, fazendo com que se ganhe mais informação, relativamente a necessidades contextuais, pelo movimento fluido das quatro pontas do tetraedro heurístico que anima a sua perspectiva pragmática (pp. 155-156).

\section{Antiessencialismo?}

Observando mais atentamente, contudo, parece-me que a maior preocupação de Zachar não é tanto o relativismo, mas o essencialismo. Zachar quer realmente afastar-se de soluções como as de Wakefield (1992), outro distinto representante daqueles que denominei acima como teóricos do "termo médio" (cf. Horwitz \& Wakefield, 2007; Horwitz \& Wakefield, 2012). Wakefield concebe uma noção de "disfunção" em termos naturalizados, o que lhe permite fundamentar a validade dos transtornos mentais como "funções naturais". Isto se explica pelo seguinte: em suas várias edições, o DSM vem definindo o conceito de transtorno mental ao redor da noção de "disfunção", e esta, por sua vez, em torno das noções de "sofrimento" ou de "incapacidade" significativos. Todo transtorno mental deve conter uma disfunção, e sofrimento ou incapacidade significativos a ela correlacionados. Mas não há no DSM qualquer explicação adicional sobre o que tais termos significariam mais exatamente. Wakefield oferece este acréscimo, naturalizando a noção e definindo-a como "disfunção prejudicial". 3

Zachar, evidentemente, aceita que um transtorno mental seja a tradução científica de uma forma de disfunção prejudicial, uma certa condição que causa sofrimento e incapacidade suficientes e necessários para a qualificação de um transtorno dentro de uma especialidade médica, mas a sua concepção de ciência se restringe, como vimos, ao modelo da comunidade imperfeita. Para Wakefield, no entanto, o sofrimento e a incapacidade por si sós não bastam. Seria preciso um conceito de disfunção suficientemente relevante para evitar confundir o transtorno com meros sofrimentos e incapacidades normais que se manifestam nas pessoas em determinadas circunstâncias eventuais. Segundo o seu ponto de vista, as disfunções realmente relevantes e diferenciais para a psiquiatria são aquelas que atingem as assim chamadas "funções naturais". Elas teriam a ver com o projeto evolutivo humano e seriam aplicáveis tanto a mecanismos físicos como mentais. E o que conta como "projeto evolutivo" seria, para Wakefield, matéria objetiva

${ }^{3}$ Traduzo assim a expressão harmful dysfunction (Wakefield, 1992), de difícil transposição para o português. 


\section{OBSERVANDO A PSIQUIATRIA}

investigada pela ciência natural. De fato, Wakefield adota para a psiquiatria o mesmo modelo dos tipos naturais pelos quais a física, a química e a biologia circunscrevem os seus objetos de pesquisa, e defende que o conjunto de propriedades ali definidos conformam uma relação de identidade entre denominação e denominado ao modo de um "essencialismo da caixa-preta" (Wakefield, 1999). Isto é, os referentes empíricos dos construtos teóricos estão sujeitos ao tribunal da investigação científica e não caracterizariam realmente aquilo que, ao meu ver, Zachar chega a chamar de um "essencialismo de facto" (cf. Zachar, 2014, pp. 121, $128,168,176,198,201)$.

\section{Pequenas confusões lógicas}

A crítica de Zachar ao essencialismo de Wakefield é correta e relevante, na minha opinião, por causa de pelo menos três pontos: porque (1) é razoável desconfiar que Wakefield favoreça uma concepção tão rósea e tão purista da ciência que talvez não leve em conta suficientemente bem o papel dos valores relativamente aos fatos (cf. Fulford, 1999); porque (2) tampouco seria exagerado dizer que a sua opção pela psicologia evolutiva, face a outras perspectivas científicas disponíveis para explicar uma disfunção prejudicial, seria uma preferência injustificada, posto que estaria baseada em argumento circular (cf. McNally, 2011, pp. 69-96); e porque (3) o próprio autor também indica que a noção de "funções naturais" de Wakefield estaria mais ligada à especulação metafísica do que propriamente a evidências materiais concretas (cf. Zachar, 2014, pp. 119-120). Apesar da correção e da relevância destes pontos, nota-se também no antiessencialismo de Zachar, uma pequena confusão entre essencialismo de facto e essencialismo de jure, ${ }^{4}$ elementos que são bem distintos e claramente diferenciados tanto nos trabalhos de Kripke (cf. 1981, p. 21, n. 21) quanto nos de Putnam (1975), evocados por ele (Zachar, 2014, p. 65). Cada um desses autores resolve a tensão lógica da designação rígida de propriedades empíricas em todos os mundos possíveis e a relação de identidade entre nomes, ou com a admissão de relações

${ }^{4}$ Os termos em latim denotam uma distinção filosófica possível (pelo menos em princípio) entre aquilo que pertence ao caso empírico particular (uma mancha de cor vermelha numa parede, por exemplo, que seria reconhecida por um conjunto de propriedades essenciais da cor vermelha verificáveis de facto) e aquilo que pertence ao caso do conceito (o conjunto de propriedades que define a priori, portanto de jure, legalmente, as regras pelas quais denomino uma mancha como algo que satisfaz ao caso da cor vermelha). 
necessárias a posteriori (Kripke, 1981), ou com o atenuante de que a noção de uma realidade física externa é uma abstração elaborada na própria experiência e sempre passível de correção (Putnam, 1975). Em outras palavras, o essencialismo de designadores rígidos seria uma assunção metafísica implícita aos nomes (Kripke, 1981), ou parte constituinte interna metafísicamente necessária das designações (Putnam, 1975), mas não ao modo de um essencialismo de facto. Trata-se simplesmente de essencialismo de jure, mera ferramenta lógica.

Esta pequena confusão acerca de tipos de essencialismo no livro de Zachar (2014) expressa-se, por exemplo, numa frase lavrada a certa altura do texto: "A nomeação, entretanto, não precisa do essencialismo" (p. 62). A frase aparece depois da discussão, naquele trecho, sobre uma tendência natural dos seres humanos de distinguir "essências" ou "tipos naturais" na experiência (pp. 55-62) — aliás como também ocorre com as noções de "realidade" e de "objetividade". Deste modo, o que Zachar realmente poderia dizer é que "a nomeação não precisa do essencialismo de facto" (assim como não precisa de um realismo de facto ou de um objetivismo de facto). Sem dar o mesmo tratamento lógico à noção de "essência" que havia dado às outras noções ("realidade", "objetividade", "evidência", "verdade" e "progresso"), o autor prossegue nesse raciocínio de aparente recusa absoluta do essencialismo até admitir, no quarto capítulo, que nós podemos pensar de maneira 362 não essencialista (cf. p. 56). Isto significaria, em princípio, que além de abjurar de uma necessidade lógica do seu próprio sistema, Zachar estaria também formulando naquela frase uma abstração. O seu propósito principal era o de livrar-se de abstrações empiricamente desnecessárias, tal como parece ser precisamente a ideia de um "pensamento não essencialista".

$\mathrm{O}$ fato de que uma classificação diagnóstica reclame a descrição de um conjunto de propriedades essenciais que a diferenciem de outras semelhantes, ou de que tenhamos necessidade lógica de diferenciar o permanente do circunstancial nas amostras do mundo empírico, ou de que precisemos diferenciar o objetivo do subjetivo, não implica por outro lado que tenhamos que reificar tipos naturais. Basta, para isto, que adotemos uma lógica plurivalente (uma lógica fuzzy, por exemplo $)^{5}$ cuja necessidade já está implícita pela própria proposta de um modelo de comunidade imperfeita. Uma classificação poderia ser satisfeita por uma amostra empírica, mas outra classificação diferente poderia também ser satisfeita

${ }^{5}$ Uma lógica fuzzy adota valores de verdade ao longo do contínuo entre 0 (falso) e 1 (verdadeiro), de modo que podemos estabelecer regras de decisão objetivas acerca de uma valoração como, por exemplo, 0,4 (mais para falso do que para verdadeiro) ou 0,6 (mais para verdadeiro do que para falso). 
mereologicamente pela mesma amostra, sem representar necessariamente qualquer problema para processos de decisão. E, do mesmo modo, uma classificação, comparada com outra do mesmo tipo, poderia conter no seu conjunto uma certa quantidade de divergência do padrão absoluto do domínio. Tudo isto é independente do fato de que identificamos "essências" no mundo empírico. O peso específico de cada uma das classificações seria dado por fatores contextuais, normativos e históricos que também entram na conta lógica de maneira mais episódica.

Talvez a sua particular rejeição do essencialismo se explique pela necessidade de distanciamento da espécie de naturalismo abraçado por Wakefield, um defensor entusiasmado de propriedades essenciais (no sentido da psicologia evolutiva) de atributos mentais. Ou então porque, apesar de tudo, talvez o autor esteja imbuído de um suposto, de uma lógica bivalente de que se definimos propriedades essenciais em um transtorno, no outro transtorno elas seriam necessariamente acidentais (Zachar, 2014, p. 134). Mas o que ocorre somente num modelo que adota uma lógica bivalente não deveria afetar o seu raciocínio, dadas as exigências lógicas plurivalentes da sua proposta. Está implícito no nominalismo instrumental que transtornos mentais são nomes que descrevem condições psiquiatricamente relevantes, o que, por si mesmo, implica distinguir "essências". Essências de jure, deixemos claro.

Uma vez admitidas as condições filosóficas da questão, todo o instrumental lógico das nomeações deveria entrar em jogo sem exceções. Nenhuma das propriedades semânticas por ele discutidas (realidade, objetividade, evidência, verdade, progresso e até mesmo propriedades essenciais) impediriam um processo de tomada de decisão com respeito a diagnóstico. Evidentemente, as propriedades mentais descritas pelos transtornos denotariam, como sempre, um essencialismo de jure, não um essencialismo de facto, ao qual se aplica realmente a crítica de Zachar, e poderiam ser perfeitamente acomodadas dentro do modelo da comunidade imperfeita.

\section{Nomes de propriedades mentais}

Alguns reparos formais adicionais ainda teriam guarida numa proposta nominalista instrumental para a psiquiatria, se o leitor me permite o uso de um linguajar um pouco mais técnico. Parto do princípio de que, na linguagem do mental, o uso de propriedades lógicas e semânticas é diferente do uso das mesmas propriedades na linguagem do mundo físico. Se aqui um nome descreve, lá, com os mesmos componentes, ele expressa. Existe uma dissimetria no uso, mas não propriamente por razões materiais ou lógicas, mas por razões pragmáticas, de modo que seria 
muito difícil superar a teoria do monismo anômalo de Davidson (2001), ou a teoria da impossibilidade da aplicação de designadores rígidos aos nomes mentalistas, defendida por Kripke (1981).

Para Davidson, não há leis que descrevam estados mentais. Qualquer relação entre um nome de um evento mental (como um transtorno, por exemplo) e o estado a que se refere teria apenas a forma de uma identidade token-token, comportaria apenas uma relação causal descritível de maneira funcional. Um token é o designador ou a marca distintiva de uma particularidade. Isto significaria dizer que embora um nome de um transtorno possa designar, do ponto de vista lógico, eventos mentais determinados, seria impossível descrevê-lo. A particularidade dos casos torna as funções de identidade aplicadas ao mundo mental demasiado opacas para servirem a inferências indutivas universais.

Por motivos não exatamente iguais aos de Davidson, já que rejeita decididamente a possibilidade de uma relação de identidade token-token para os eventos mentais, Kripke (1981, p. 144, n. 73), também conclui da mesma forma que aquele autor: nomes de propriedades mentais não são apropriados para inferências indutivas. Na visão de Kripke, entretanto, nomes de eventos mentais, em particular, não comportam designadores rígidos que mantenham relações de identidade 364 possíveis na prática (pp. 134-155).

Se aceitamos argumentos como esses, favoráveis ao anomalismo dos eventos mentais, podemos manter a teoria da identidade de Davidson e a lógica da nomeação de Kripke, favorecendo inferências abdutivas e a designação implicada pela nomeação apenas como expressão. ${ }^{6}$ Tratamos de inferir, em vez do objeto referido pela designação, o tipo de expressão de que se trata. Tipos de expressão também são nomes, naturalmente. E nomes que têm a forma lógica de designadores, mas sem a necessidade do designado. Este, me parece, é um uso peculiar aos nomes de estados mentais, completamente desfavoráveis, como dizem aqueles autores, a inferências universais mais estritas. Nomes de eventos mentais nos obrigam a uma compreensão distinta daquela de nomes de objetos empíricos capazes de designação. No universo específico do mental faríamos inferências inseguras, sujeitas em

\footnotetext{
${ }^{6}$ Uma inferência abdutiva é uma forma de raciocínio indutivo bem menos segura. Trata-se da escolha pela melhor explicação de um fenômeno empírico ou de um caso singular, dentre várias possibilidades lógicas factíveis. Evidentemente a eleição do que se considera como "a melhor explicação" é o resultado do consenso de uma comunidade de especialistas. A abdução difere da indução propriamente dita porque esta é uma inferência baseada numa coleção extensa de fatos empíricos semelhantes. No caso das ciências do mental, a indução não se aplica. Cabem somente abduções.
} 
muito maior grau a todo tipo de incertezas, isto é, a interferências culturais, históricas e políticas, assim como também à sobreposição a mais de uma possibilidade de decisão entre distintas classificações competidoras. Nada que uma espécie de lógica polivalente não chegue a dar conta, por outro lado.

Acredito, assim, que o recente livro de Zachar, com sua ênfase em redes causais implicadas pelas quatro pontas do seu tetraedro gramatical (cf. Zachar, 2014, p. 155), deveria, de acordo com a importância e o impacto dos seus alcances filosóficos, canalizar suas conclusões acerca do essencialismo de facto a favor de um essencialismo de jure. Com uma lógica mais robusta, Zachar atingiria o máximo grau de objetividade pragmática possível. Contemplaria ainda mais plenamente os problemas específicos da psiquiatria com as suas interessantes e atualizadas soluções filosóficas, tão necessárias para os pungentes desafios contemporâneos da clínica dos transtornos mentais.

\section{Referências}

Banzato, C., \& Zorzanelli, R. (2014, março). Superando a falsa dicotomia entre natureza e construção social: O Caso dos Transtornos Mentais. Revista Latinoamericana de Psicopatologia Fundamental, 17(1), 100-113.

Davidson, D. (2001). Mental Events. In D. Davidson, Essays on Actions and Events (2 $^{\text {nd }}$ Ed., pp. 207-224). Oxford: Clarendon Press. (Trabalho original publicado em 1970).

Fulford, K. (1999). Nine Variations and a Coda on the Theme of an Evolutionary Definition of Dysfunction. Journal of Abnormal Psychology, 108(3), 412-420.

Goodman, N. (1951). The Structure of Appearance. Cambridge, MA: Harvard University Press.

Goodman, N. (1972). Problems and Projects. Indianapolis: Bobbs-Merrill.

Graham, G. (2010). The Disordered Mind: An Introduction to Philosophy of Mind and Mental Illness. London: Routledge.

Horwitz, A., \& Wakefield, J. (2007). The Loss of Sadness. How Psychiatry Transformed Normal Sorrow into Depressive Disorder. New York: Oxford University Press.

Kripke, S. (1981). Naming and Necessity $\left(2^{\text {nd }}\right.$ printing). Cambridge, MA: Harvard University Press.

McNally, R. (2011). What is Mental Illness? Cambridge, MA: Harvard University Press.

Micale, M. (2008). Hysterical Men. The Hidden Hystory of Male Nervous Illness. Cambridge, MA: Harvard University Press.

Micale, M. (2014). The Ten Most Important Changes in Psychiatry Since World War II. History of Psychiatry, 25(4), 485-491. 
Putnam, H. (1975). Mind, Language and Reality. Philosophical Papers (vol. 2). Cambridge: Cambridge University Press.

Ross, P. (2005). Sorting Out The Concept Disorder. Theoretical Medicine and Bioethics, 26(3), 115-140.

Serpa Jr., O. (2014). Uma metafísica das classificações em psiquiatria. Physis Revista de Saúde Coletiva, 24(4), 1361-1366.

Szasz, T. (1974). The Myth of Mental Illness: Foundations of a Theory of Personal Conduct. New York: Harper. (Trabalho original publicado em 1961).

Wakefield, J. (1992). Disorder as Harmful Dysfunction: A Conceptual Critique of DSM-III -R's Definition of Mental Disorder. Psychological Review, 99(2), 232-247.

Wakefield, J. (1999). Mental Disorder as a Black Box Essencialist Concept. Journal of Abnormal Psychology, 108(3), 465-472.

Zachar, P. (2014). A Metaphysics of Psychopathology. Cambridge, MA: The MIT Press.

\section{Resumos}

\section{(Naming and psychiatry)}

The more intense the discussions about classifications, the more we need to pay careful attention to the logic by which the clinic of mental disorders is defined and developed. Its specific classification issues should be solved by the most appropriate tool for that kind of task, i.e., taking into account its nature, a many-valued logic. For that reason, I conduct in this paper a brief discussion on some logical aspects of the instrumental nominalism proposed by Peter Zachar.

Keywords: Psychiatry, naming, instrumental nominalism, DSM-5

(Psychiatrie et nomination)

Plus les discussions sur les classifications deviennent intenses, plus nécessaire devient l'attention détaillée que l'on doit payer à la logique par laquelle la psychiatrie encadre et développe la clinique des troubles mentaux. Ses problèmes particuliers de nomination devraient être résolus par l'outil le plus approprié pour ce genre de travail, qui devrait être, compte tenu de la nature des problèmes, une logique polyvalente. Dans cet article, je mène une brève discussion sur certains aspects logiques du nominalisme instrumental proposé par Peter Zachar.

Mots clés: Psychiatrie, nomination, nominalisme instrumental, DSM-5

(Psiquiatría y nombramiento)

Entre más intenso sea el debate sobre las clasificaciones psiquiátricas, más exigente se vuelve la necesidad de una cuidadosa atención hacia la lógica a través de 


\section{OBSERVANDO A PSIQUIATRIA}

la cual la psiquiatría demarca y desarrolla la clínica de los trastornos mentales. Sus problemas particulares de nombramiento deberían ser resueltos por la herramienta más apropiada para esta tarea, que debería ser, considerando su naturaleza, una lógica plurivalente. Teniendo en cuenta lo anterior, realizo una breve discusión sobre algunos aspectos lógicos del nominalismo instrumental propuesto por Peter Zachar.

Palabras clave: Psiquiatría, nombramiento, nominalismo instrumental, DSM-5

(Psychiatrie und Benennung)

Je intensiver die Diskussionen um die Einstufungen im Bereich der Psychiatrie werden, desto notwendiger wird es, die Logik aufmerksam zu verfolgen, welche die Klinik psychischer Störungen definiert und lenkt. Ihre spezifischen Benennungsprobleme sollten mittels eines für diese Aufgabe geeigneten Werkzeuges gelöst werden, d.h., mittels einer mehrwertigen Logik. Angesichts dieser Lage, bietet dieser Artikel eine kurze Diskussion über einige logische Aspekte des von Peter Zachar vorgeschlagenen instrumentellen Nominalismus.

Schlüsselwörter: Psychiatrie, Benennung, instrumenteller Nominalismus, DSM-5

\section{(精神病学和分类命名)}

关于精神分析学的分类 (classificações), 有很多的激烈争论, 越是有争论, 越需要我们仔细注意精神障碍 (transtornos mentais) 的临床实践方面的逻辑。具 体的关于命名 (nomeação) 的问题应该用最合适的工具来解决, 这种工具应该是 包容多元价值的逻辑 (lógica plurivalente)。鉴于此, 我们讨论了Peter Zachar 提议的被称命名主义工具 (nominalismo instrumental) 的逻辑性。

关键词: 精神分析法, 命名, 命名主义, DSM-5

Citação/Citation: Almeida, J.J.R.L. de (2015, junho). Psiquiatria e nomeação. Revista Latinoamericana de Psicopatologia Fundamental, 18(2), 352-368.

Editores do artigo/Editors: Prof. Dr. Claudio E. M. Banzatto e Profa. Dra. Rafaela Zorzanelli

Recebido/Received: 18.2.2015/ 2.18.2015 Aceito/Accepted: 5.3.2015/3.5.2015 
Copyright: (C) 2009 Associação Universitária de Pesquisa em Psicopatologia Fundamental/ University Association for Research in Fundamental Psychopathology. Este é um artigo de livre acesso, que permite uso irrestrito, distribuição e reprodução em qualquer meio, desde que o autor e a fonte sejam citados / This is an open-access article, which permits unrestricted use, distribution, and reproduction in any medium, provided the original authors and sources are credited.

Financiamento/Funding: O autor declara não ter sido financiado ou apoiado / The author has no support or funding to report.

Conflito de interesses/Conflict of interest: $\mathrm{O}$ autor declara que não há conflito de interesses / The author has no conflict of interest to declare.

\section{João José R. L. de Almeida}

Doutor em Filosofia pela Universidade Estadual de Campinas - Unicamp (Campinas, SP, Br), com pós-doutorado no MIT (Cambrigde, EUA); Membro do Grupo de Estudos Interdisciplinares da Saúde, vinculado à Pós-Graduação em Ciências Humanas e Sociais Aplicadas (FCA/Unicamp (Limeira, SP, Br).

Faculdade de Ciências Aplicadas da Unicamp

Rua Pedro Zaccaria, 1300

Caixa Postal, 1068

13484-350 Limeira, SP, Br

e-mail: joao.almeida@fca.unicamp.br 